\title{
The vision of delivery drones
}

\author{
Call for a technology assessment perspective
}

\author{
Michael Nentwich, Institute of Technology Assessment (ITA) of the Austrian Academy of Sciences (ÖAW), \\ 1030 Vienna, Apostelgasse 23 (mnent@oeaw.ac.at), (1) orcid.org/0000-0003-2269-0076 \\ Delila M. Horváth (delila.horvath@gmail.com), (1) orcid.org/0000-0003-4112-8070
}

The vision of drone-based delivery is not without presuppositions. To fully realize this vision, it is imperative to overcome the many technical and regulatory obstacles. Given the considerable depth of engagement of this technology - the airspace around us, which has so far only been used by birds and the occasional helicopter, would change profoundly - a number of typical technology assessment (TA) questions are on the table: Are there any safety concerns? Are there any environmental risks? Could criminals or terrorists misuse the technology? Are we going to face societal conflict in view of divergent interests? Is the current regulatory framework sufficient, or do we need new rules? This article provides a broad outline of this topic, gives first answers to the above mentioned questions, and concludes that an encompassing participatory TA study is needed.

\section{Vision Lieferdrohnen}

Aufruf zur Betrachtung aus Perspektive der Technikfolgenabschätzung

Die Vision eines drohnenbasierten Lieferverkehrs ist nicht voraussetzungslos. Viele regulative und technische Hürden müssen noch genommen werden, um sie Wirklichkeit werden zu lassen. Aufgrund der großen Eingriffstiefe dieser Technologieentwicklung - immerhin würde sich der uns umgebende Luftraum, der bislang nur von Vögeln und gelegentlichen Hubschraubern benutzt wird, gravierend ändern - stellen sich eine Reihe von typischen Fragen der Technikfolgenabschätzung (TA): Bestehen Sicherheitsbedenken? Gibt es Umweltrisiken? Kann die Technologie für kriminelle oder terroristische Zwecke missbraucht werden? Besteht ein gesellschaftliches Konfliktpotenzial angesichts unterschiedlicher Interessen? Reicht die aktuelle Regulierung aus oder müssen neue Regeln geschaffen werden? Dieser Artikel stellt das Thema in groben Zügen dar, gibt erste Antworten auf die genannten Fragen und erkennt die Notwendigkeit einer umfassenden, partizipativen TA-Studie.

Keywords: delivery drones; transport market; environmental, health and safety issues; ethical, legal, societal impacts

This is an article distributed under the terms of the Creative Commons Attribution License CCBY 4.0 (https://creativecommons.org/licenses/by/4.0/)

https://doi.org/10.14512/tatup.27.2.46

Submitted: 07. 03.2018. Peer reviewed. Accepted: 11. 05.2018

\section{Introduction}

Companies worldwide imagine a world in which everyday commodities will be delivered by drones through the air, and this emerging market for drone delivery is expanding. Following initiatives of small enterprises, for instance delivering pizza in New Zealand, large corporations as diverse as Amazon, Google (Project Wing), DHL, Mercedes-Benz and many others have started to invest a lot of resources in testing delivery by drones and have been lobbying for making this service a reality. Numerous start-ups and postal operators are launching delivery services by drones all around the word, in particular in Asia and Africa, testing the market and the legislative frameworks with this novel approach (for a market overview see Nentwich and Hórvath 2018, chapter 4).

This vision of drone-based delivery is not without presuppositions though. To realize the vision of drone-based delivery, many technical, regulatory and societal questions would have to be solved. Given the considerable depth of engagement - considering that the airspace around us, which has so far only been used by birds and the occasional helicopter, would change profoundly - a number of typical technology assessment (TA) questions are on the table: Are there any security concerns? Are there any environmental risks? Could criminals or terrorists misuse the technology? Are we going to face societal conflict given that divergent interests are involved? Does the current regulatory framework suffice or do we need new rules?

This article is based on an explorative report (Nentwich and Hórvath 2018) expanding on previous literature (Moe 2013; ITA 2014; POST 2014; Rao et al. 2016; Krieger-Lamina and Nentwich 2016). It gives first answers to the above-mentioned questions and is mainly based on an extensive Internet and literature search, several interviews with experts, and analytical considerations.

\section{Technical and legal preconditions}

There are two important preconditions for the launch of delivery services by drones: it has to be technically feasible and safe, and the law must allow autonomous flights in principle. Drone 
delivery seems only reasonable when they can be operated in an autonomous mode - except for very special scenarios (e. g. occasional fast delivery to remote areas). Otherwise, the main reasons for launching such service (e. g. cost reduction, automation, and speed) would be compromised if pilots were needed for each drone. However, to operate a drone autonomously presents technical challenges.

The main challenge regarding the operation of autonomous delivery drones is the development of robust sense and avoid ( $\mathrm{S} \& \mathrm{~A}$ ) technology. This term refers to a drone's capability to take-off, fly and land at the intended location and in the intended manner without colliding on the way. In order to do so, the drone needs a) a geo-location device which operates continuously and
The other main obstacle is the present state of regulation. Evidently, delivery drones do not belong to the category of lightweight flying objects (to which toy equivalents belong) because they need to carry a load in addition to the equipment needed for autonomous flying (such as cameras and other sensors, etc.). Consequently, delivery drones could only be employed under special conditions (e. g. licence). For on-board cameras and other equipment, a special additional licence granted by the aeronautical or aviation authorities would be required. However, so far, the law does not cover autonomous drones and therefor does not permit their use in Europe. In addition, under current regulation authorities allow the flight of delivery drones over populated urban areas, only on a case-by-case basis, which is obvi-

\section{To realize the vision of drone-based delivery, many technical, regulatory and societal questions would have to be solved.}

accurately, b) clear vision with the help of cameras (or radar), and c) well-developed algorithms to execute accurate landing. Moreover, delivery drones would need to exhibit technical readiness to overcome challenges caused by the weather, physical obstacles on the way (tall buildings, electric poles, cables, flying birds, other drones, and not least humans), and internal malfunctions. It has not yet been established which S \& A technologies (or which combination) would be the most reliable and cost-efficient. In particular, both the development and testing of Global Positioning Service (GPS), radar, infrared and other technologies are still ongoing. To this day, the threat of drones crashing (into another object or into each other) remains a challenge, which technicians have yet to solve satisfactorily. Furthermore, delivery drones would need to be able to respect the designated no-fly zones (geo-fencing), i. e. they need to have up-to-date access to the respective databases or air signals. In addition, drones must be able to autonomously and constantly communicate with and coordinate other air traffic and air control. Finally, battery capacity and thus reach (the distance a drone could cover) are additional important factors to consider, as are cargo weight restrictions. An Austrian pilot project in summer 2017 showed that flights with parcels weighing $3.5 \mathrm{~kg}$ could be transported for a distance of up to $10 \mathrm{~km}$ (Futurezone 2017). Most technicians seem optimistic that all of these challenges can soon be overcome, with some experiments and pilot tests already confirming this, others, however, disconfirm (Futurezone 2018). Our interim conclusion is that several technical aspects of autonomous drones still need further development and a few years of testing before it would be safe enough to launch extensive commercial delivery services - similar to driverless cars in general. Furthermore, functioning infrastructure, in particular landing spots, must be established. Several options are currently under development, including small movable platforms on a cantilever next to the window (e.g. http://win-port.de). ously not suitable for a business model relying on regular deliveries. As a result, legal frameworks would have to be adapted for delivery drones, for instance with an additional drone category with special rules. Subsequently, there would be a need for regulation in order to enable mass deployment, especially should delivery services by drones be authorised in urban areas. The regulatory debate has been under way for a couple of years (AAE/3AF 2015, p. 52 ff.) but is still open, in particular in respect to autonomous flying ${ }^{1}$.

\section{Possible applications}

The preliminary assessment of the possible impact of the introduction of commercial delivery drones outlined in the next sections refers to two potential applications as reference points. Based on the assumption that the two above-mentioned preconditions have been met, these applications have been extrapolated from the various experiments and activities from start-ups and major players and are thus meant to represent their visions of the future.

The first application concerns the widespread delivery of all kinds of small goods (parcels) by drones instead of (or in combination with) delivery vans and trucks. In this scenario - we will call it, non-technically speaking, the "pizza scenario" -, drones would be fulfilling the function of the so-called "last mile delivery": various logistics providers would use the urban (and rural) airspace on a regular basis to deliver goods to consumers. The idea behind this would be to be able to deliver even faster

1 See the current proposals by the European Aviation Safety Agency (EASA): easa.europa.eu/easa-and-you/civil-drones-rpas/drones-regulatory-frameworkbackground; and the respective regulatory process at EU level where a political agreement seems to have been reached at the end of 2017 (easa.europa.eu/ document-library/opinions/opinion-012018). 
than presently possible, in particular given the traffic jams on the ground. "Amazon Prime Air" is one example of this business model, but it is not yet operative. There are, however, many other examples for delivery services for food and other commodities worldwide, for instance: pizza in New Zealand, fast food in Iceland, or coffee in Switzerland and Dubai (Nentwich and Hórvath 2018, p. 24 ff.).

The second application - we will call it the "emergency scenario" - is less encompassing: the delivery service by drones would take place only in one or several niche markets. The commodities transported by the drones could be special goods in the medical field - like blood supplies, which would be routinely transported between hospitals, pharmacies, and practitioners -, or other emergency goods. ${ }^{2}$ Another potential niche market could be the regular supply of goods to remote areas to where there are no roads or where no other connection exists during specific seasons (for instance in rural Africa or in alpine regions). For an overview, see Nentwich and Hórvath (2018, p. 26).

\section{Potential impacts of employing drones for deliveries}

Amongst the varied potential impacts of drone deliveries, this short article will only feature a selection and includes the following issues: changes in consumer behavior, resilience of the delivery system, protection against misuse. For a complete overview, though not an in-depth analysis, see Nentwich and Hórvath (2018).

\section{Health, safety and security}

There are two types of health risks resulting from accidents. First, malfunction of the navigation system, in particular in bad atmospheric conditions, may lead to accidents. Especially in urban areas with a dense population, collisions of drones with humans are possible, and injuries quite likely as the rotors are sharp and loaded drones weigh several kilograms. As long as delivery drone systems have not yet been put in place, and depending on the type of application, estimating the likelihood of accidents is presently still difficult.

Another potential health risk stems from the drone's load. In the event of a crash of a drone carrying a dangerous good, various scenarios with far-reaching consequences are conceivable. The definition of what counts as dangerous goods would have to be refined: for instance one may question whether blood samples of ill people, medical probes or vaccines should be included in such definition as these could potentially contaminate the environment or pose a direct threat to people. There may even be the possibility of prohibiting the transport of dangerous goods altogether.

2 For instance, Zipline Int. delivers blood samples and medical supplies, flyzipline.com; Matternet specialises in emergency goods, mttr.net.
Furthermore, drones disguised with the logo of a delivery firm could easily be misused for illegal purposes, e.g. trafficking (drugs, weapons), spying, carrying bombs, or the drone itself could be used as a kamikaze weapon (e. g. AAE/3AF 2015, p. 49 f.).

\section{Environment}

As drones use the environment (both natural and man-made), they are also a potential risk to it. The first concern is the drones' effect on wildlife, and birds in particular. When drones intrude into the habitat of animals, there is a double risk: either the animals may be harmed, or they could be a threat to the effective operation of drones. With regard to the latter, such a scenario has already been documented in Austria when eagles mistook drones for food (The Independent 2015). Regarding the former, there are concerns that the safety of birds could be at risk because of the possibility of collision, quite similar to the risk associated with wind turbines. It must be noted that not only wildlife could be affected: depending on the territory the drones would be allowed to fly through, they could have an impact on various domesticated animals (pets and farm animals) as well.

Even without the risk of collisions, the drones' noise and frequent presence in the animals' habitats may be a stressor for them, similar to nearby roads. The effect of noise produced by drones on wildlife has not been studied yet, but serious concerns exist and should be taken into consideration. Several aspects of must be considered: altitude, flight corridors, no-fly zones, and landing sites.

Another possible environmental risk is debris. Regardless whether debris results from collision or from forgotten or abandoned goods, the question of waste poses another series of challenges. Consequently, this raises questions regarding responsibility and actual response: who would be responsible for cleaning up debris, and who would bear the costs of damage or compensation? This issue prompts comparison with fly tipping. Here, too, the question regarding taking responsibility remains difficult to answer.

\section{As drones use the natural}

\section{and man-made environment,}

\section{they are also a potential risk to it.}

From a TA perspective, another environmental aspect to consider is energy consumption. Drones need electricity, and although each individual flight would not consume much, the overall picture of a universal drone delivery system may be different, in particular when compared with current deliveries by car (possibly electric vans in the future) in which many parcels can be transported at once. In a recent research article, Stolaroff et al. (2018) conclude that for parcels up to $0.5 \mathrm{~kg}$ the energy 
balance is in favour of drones. However, the overall assessment may be different when putting the entire infrastructure into perspective. Overall, a serious assessment of the ecological footprint (life-cycle assessment) is necessary, including - amongst other factors - the lifetime of drone batteries.

\section{Labour market}

The technology of drones and its potential effect on the job market are another area of concern (OECD 2015). The transport and logistics industry employs large numbers of drivers to deliver parcels in person on the so-called "last mile". With the advent of 24/7 online shopping, the market segment of delivering to customers' homes has increased considerably, as has the labour market for parcel pickers and delivery van driver. If the use
As the process of automation would result in less need for human workers, the group of unskilled workers could suffer most (Forbes 2017; Goldman Sachs o. J.; Reuters 2017).

\section{Ethics}

What behaviour will be pre-programmed into the software of drones for the scenario of an impending, no longer avoidable accident? Similar to algorithms within the context of driverless cars, drones must be able to make a number of decisions in split seconds prior to an event in order to remain operative. For driverless cars, these tricky issues have already seen extensive discussion among ethicists and technologists (Maurer et al. 2015). A similar discussion for drones is still missing (for a first contribution see Luppicini and So 2016).

\section{Now is the perfect time for carrying out an encompassing technology assessment study on drones - and to induce a public debate about it with all concerned stakeholders as well as citizens.}

of drones for the last mile should become more common, employment of delivery drivers will eventually shrink.

Such effects would depend on the specific type of application and the delivery modes that have been put in place. Evidently, the labour market for delivery drivers in the pharmaceutical industry is much smaller than in the consumer goods sector. In cases where drones take off from automated intermediate storage facilities, van drivers would be out of business in the long run (except for when it comes to large and/or heavy parcels that could not be carried by drones). If drones should take off from delivery vans, there would still be a need for drivers - unless those vans would eventually become driverless cars themselves. Still, their numbers would be reduced because using drones for the last mile is purportedly much more time efficient: not only are drones faster than a human walking up the stairs, more drones could be taking off from one van at the same time. This would lead to faster turnover times for delivery vans in which there would still be only one driver.

To the authors' knowledge, no specific scientific study on last mile delivery has yet been published. However, several studies examine the process of digitalisation and automation in various job markets in different countries (EPTA 2016; Frey and Osborne 2013; Čas et al. 2017). Economists are split over the exact figures, but agree in predicting huge job losses for the general transport sector (taxi drivers, lorry drivers, etc.). Further research is needed.

It is also important to acknowledge that elementary occupations, serve as a social and economic safety net for those individuals who lack an education or vocational/specific training.
The typical and often quoted scenarios, in which some kind of damage is unavoidable, raise different ethical concerns over drone behaviour. For instance: what if a drone which carries a life-saving cargo can avoid crashing into a human only by abandoning or destroying the parcel that could have saved someone else's life (e. g. a parcel containing a human organ for transplant). Such ethical question and similar ones would have to be answered beforehand, with relevant drone behaviour responses being programmed into the software. Similar to the discussion about autonomous cars, the question arises whether it should be the programmer who decides in advance, the drone manufacturer, the delivery service enterprise, the sender or the recipient of the parcel, or rather society at large and thus the legislator. How would the implementation of these decisions on drone behaviour be overseen? Clearly, answering all these questions is not easy (Krieger-Lamina and Nentwich 2016). For the drone to be able to take whichever decision, permanent surveillance and analysis of the environment is a precondition.

Incidentally, this ethical dilemma is also present in the case of a delivery service being restricted to emergency parcels (the second type of application, i. e. our "emergency scenario"). Taking into consideration that an emergency represents a situation where decision-making is difficult, the question of what constitutes an emergency and what does not remains unanswered. The delivery of organs for transplant may safely be considered an emergency, but what about other cases such as the transport of medical probes and blood samples?

In the second type of application, one may even go one step further: would drone delivery services in urban settings be the 
privilege of medical entities only? If so, what counts as a medical entity? Would there be strict regulation of who is allowed to fly and who is not, and how to limit and punish misuse of privileges? If strict controls, time restrictions, flight corridors etc. were in place, such service would be a scarce commodity, probably incurring higher prices. For instance, a certain patient's blood could be given priority because she or he paid extra fees to obtain results faster. This is a typical TA dilemma, which could be termed the "drones' divide": in one scenario only the rich might be in a position to afford it (yet would still use common/ shared airspace), which may lead to an additional difference in the quality of healthcare. The same set of questions may also be asked for other services.

\section{Further potential areas of societal conflict}

At least two major issues have the potential to raise the public's concern and to cause societal conflict: noise pollution and negative aesthetic impact on airspace: Like residents near roads or airports, residents living directly under the air corridors for regular drone delivery flights could also suffer from noise pollution. It is noteworthy to state that with our first application scenario, the pizza scenario, heavy drone traffic would develop over time. Whilst a single drone with eight electrical mini engines is not very noisy (unless it is very near), many of them at the same time certainly would be. Even if it were assumed that later generations of drones emit less noise, there would still be a limit to further improvements, as it is unlikely that airflow around the

\section{Many questions remain unanswered: they concern the commercial use of drones, the technical, legislative and societal aspects as well as safety and environmental risks.}

\section{Protection of privacy}

If parcel delivery by drones becomes a (legally) accepted service, the technology has the potential to affect and possibly conflict with privacy. Today, even without large numbers of drones in the air, this has already become an issue. Many toy drones in particular are equipped with cameras, even though this violates the law, unless a specific licence has been obtained, thereby alarming neighbours when the drone flies over one's land or approaches one's balcony. Numerous articles exist in the mass media addressing the issue (see for example Consumer Reports 2016; The Next Web 2017; Recode 2017), and several companies offer anti-drone devices, like drone guns, for self-help "law enforcement" purposes. Dutch police apparently trains falcons for drone hunting (Futurezone 2016).

Although taking pictures, filming or audio surveillance is not amongst the main purposes of delivery drones, they still need to sense where they are going (and constantly survey their environment). Consequently, they are equipped with technology that can "see", helping the drone with orientation. The data generated by these sensors during the flight could be deleted immediately. However, it may be legally required to keep a record of a flight, e.g. to prove the drone has not caused any damage or has observed aviation laws. Such a scenario seems likely as it parallels similar developments in other areas, e. g. black boxes in airplanes, tachographs in lorries and similar on-board recording devices in cars in the near future. Such devices generate, record and store video material coupled with location data and time stamps. All this data can be quite sensitive should people be identifiable from the recordings. Birds'-eye views from private properties, too, may be sensitive, as are visual recordings of public buildings (e. g. parliament buildings) or military facilities. many rotors can be avoided. This is similar to the noise produced by car tyres, which is, together with the airflow around the car's body, louder than that of the engine when travelling above a certain speed. Hence, even the most noise reduced electrical engines cannot ensure altogether silent e-cars or drones.

Besides evident noise pollution along highly used air corridors, noise emittance through delivery manoeuvers close to customers, particularly in densely populated urban areas, should not be underestimated. Only the noise produced by the expected air traffic in the second application scenario, the emergency scenario, would be of minor concern. For the first application scenario, noise pollution can safely be deemed a problem, which, if unsolved, may lead to resistance in the population. This raises the question how society would decide where drones should or would be allowed to fly in order to reduce noise pollution. Nofly zones may be part of the solution, as would be corridors high above street level and away from buildings. However, is there any solution for the last mile, i. e. the surroundings of the prospective landing spots close to the customers?

In the same way that the aesthetics of power lines and wind parks have been questioned, the aesthetic of swarming drones in the lower airspace is likely be questioned by parts of the population. At first, this may sound like a luxury problem, and society has indeed accepted many similar compromises in the past: there are fewer untouched natural landscapes, and in urban areas, it has become the norm to utilize the ground level for traffic, street furniture and appliances. Furthermore, opinions on the aesthetic value of different types of buildings and infrastructure will always remain divided. However, the authors of this article assume that extensive use of currently empty airspace could well trigger public resistance against a new and qualitatively different exploitation of and intrusion in a common good. 


\section{Preliminary conclusions}

As can be seen, many questions regarding the commercial use of drones remain unanswered. They concern the technical, legislative as well as societal aspects, safety, and environmental risks. The answers to them will differ when the different application scenarios are considered. In our "pizza scenario" with omnipresent delivery drones forming part of everyday reality, the impact on society will evidently be more severe than in the second, more restrictive application scenario with deliveries only in special cases. Whilst implementing the so-called "emergency scenario" would still require considerable preparation, both in technical and legal terms, establishing such a niche market would probably face less opposition. By contrast, the first application scenario not only requires much more sophisticated infrastructure and regulation, it also raises some potentially controversial questions.

From a TA perspective, these questions cannot be answered without in-depth interdisciplinary examination. Our study only provides a snapshot or preliminary stocktaking of the issues involved; it can be expected that some of the points raised may prove less controversial or turn out to be unimportant, but more issues that are salient could well be discovered. Moreover, many of the identified issues concern core values, and the technology touches upon the private lives of a large number of individuals. To give a few examples: the relationship between economic interests and the protection of wildlife is not an obvious one; the question of the aesthetic consequences of mass-droning is difficult to answer in a top-down manner; noise is another issue where society constantly searches for compromises.

As the technology has almost matured and many commercial entities are readying themselves, now would be the time to open up debate and examine the possible opportunities and risks of such a service. Conducting a combined expert and stakeholder/lay participatory TA study is highly recommended. A participatory approach would allow for the inclusion of the informed views of citizens and those potentially affected, not

\section{We have a window of opportunity to}

\section{shape the path of drone development}

$$
\text { through anticipatory governance. }
$$

least because the topic involves value-based decisions. Consequently, the proposed study would try to answer the question which of the above-mentioned application scenarios (or any others that may arise) is wanted by society, and under what conditions?

On a final note, the authors of this article are certain that the timing for carrying out such an encompassing study now - and for the inclusion of a public debate about it - would be perfect.
Today, the technology may not yet be at its full potential, and commercial actors may not have invested heavily in their business models yet. To translate this into TA language: currently there is a window of opportunity to overcome the well-known control or Collingridge dilemma. Today, anticipatory governance aimed at shaping the technological and economic path is still an efficient and effective option.

\section{References}

AAE/3AF (2015): Present and future of civilian drones. AAE Dossier 40/3AF Cahier 16. Paris: Air and Space Academy/French Aerospace Society. Online available at http://espas.eu/orbis/sites/default/files/generated/document/en/D40_ Ebook_UK.pdf, last accessed on 09.05.2018.

Čas, Johann; Rose, Gloria; Schüttler, Lisa (2017): Robotik in Österreich. Kurzstudie Entwicklungsperspektiven und politische Herausforderungen. Vienna: ITA. Online available at http://epub.oeaw.ac.at/ita/ita-projektberichte/2017-03. pdf, last accessed on 09.05.2018.

Consumer Report (2016): Drone privacy. is anyone in charge? Online available at https://www.consumerreports.org/electronics/drone-privacy-is-anyonein-charge/, last accessed on 14.05.2018.

EPTA - European Parliamentary Technology Assessment (2016): The future of labour in the digital era. Ubiquitous computing, virtual platforms, and real-time production. Vienna: ITA. Online available at http://epub.oeaw. ac.at/ita/ita-projektberichte/EPTA-2016-Digital-Labour.pdf, last accessed on 09.05.2018.

Forbes (2017): Should package delivery be automated with drones? A look at the pros and cons. Online available at https://www.forbes.com/ sites/quora/2017/04/17/should-package-delivery-be-automated-withdrones-a-look-at-the-pros-and-cons/\#236b19561bc9, last accessed on 14. 05.2018.

Frey, Carl B.; Osborne, Martin A. (2013): The future of employment: How susceptible are jobs to computerisation? Oxford: Martin Programme on the Impacts of Future Technology.

Futurezone (2016): Niederländische Polizei trainiert Adler für Drohnenjagd. Online available at https://futurezone.at/digital-life/niederlaendischepolizei-trainiert-adler-fuer-drohnenjagd/178.424.561, last accessed on 14. 05.2018

Futurezone (2017): TU Graz testet Drohnen als Paketzusteller. Online available at https://futurezone.at/science/tu-graz-testet-drohnen-alspaketzusteller/274.382.090, last accessed on 14. 05.2018.

Futurezone (2018): Video. Drohne der russischen Post knallt in Hauswand. Online available at https://futurezone.at/digital-life/video-drohne-der-russischenpost-knallt-in-hauswand/400014766, last accessed on 14.05.2018.

Goldman Sachs (o. .).: Drones. Reporting for work. Online available at http://www.goldmansachs.com/our-thinking/technology-driving-innovation/ drones, last accessed on 14.05.2018.

ITA (eds.) (2014): Drohnen - fliegende Alleskönner? ITA-Dossier no. 6. Vienna: Institute of Technology Assessment. Online available at http://www.austriaca. at/ita/ita-dossiers/ita-dossier006.pdf, last accessed on 09.05.2018.

Krieger-Lamina, Jaro; Nentwich, Michael (2016): Zivile Autonome Fahrzeuge zu Land, in der Luft und zu Wasser. TA16 "Smart New World - Was ist smart an smarten Technologien?" Vienna: ITA. Online available at https://www. oeaw.ac.at/ita/fileadmin/redaktion/Veranstaltungen/konferenzen/ta16/ ta16-krieger-lamina-nentwich.pdf, last accessed on 09.05.2018. 
Luppicini, Rocci; So, Arthur (2016): A technoethical review of commercial drone use in the context of goverance, ethics, and privacy. In: Technology in Society 45, p. 109-119.

Maurer, Markus; Christian, Gerdes; Lenz, Barbara; Winner, Hermann (2015): Autonomes Fahren. Technische, rechtliche und gesellschaftliche Aspekte. Wiesbaden: Springer Vieweg.

Moe, Åke Refsdal (2013): Take-off for civilian drones. Blog. Online available at http://teknologiradet.no/english/take-off-for-civilan-drones, last accessed on 09.05.2018.

Nentwich, Michael; Hórvath, Delila Mercédesz (2018): Delivery drones from a technology assessment perspective. Overview report, No.2018-01. Vienna: ITA. Online available at http://www.austriaca.at/0xc1aa5576_0x00377231.pdf, last accessed on 09. 05.2018.

OECD - Organization of Economic Co-operation and Development (2015): Employment outlook 2015. Paris. DOI: 10.1787/empl_outlook-2015-en.

POST (2014): Civilian Drones. POST Notes No. 479, London: Parliamentary Office of Science and Technology. Online available at http://researchbriefings.files. parliament.uk/documents/POST-PN-479/POST-PN-479.pdf, last accessed on 14. 05.2018

Rao, Bharat; Goutham Gopi, Ashwin; Maione, Romana (2016): The societal impact of commercial drones. In: Technology in Society 45, p. 83-90.

Recode (2017): Federal privacy laws won't necessarily protect you from spying drones. Online available at https://www.recode.net/2017/3/15/14934050/ federal-privacy-laws-spying-drones-senate-hearing, last accessed on 14. 05.2018 .

Reuters (2017): U.S. commercial drone use to expand tenfold by 2021. Online available at https://www.reuters.com/article/us-usa-drones/u-scommercial-drone-use-to-expand-tenfold-by-2021-government-agencyidUSKBN16S2NM, last accessed on 14.05.2018.

Stolaroff, Joshuah; Samaras, Constantine; O’Neill, Emma; Lubers, Alia; Mitchell, Alexandra; Ceperley, Daniel (2018): Energy use and life cycle greenhouse gas emissions of drones for commercial package delivery. In: Nature Communications 9 (1), p. 409. Online available at https://www.nature.com/articles/ s41467-017-02411-5.pdf, last accessed on 14.05.2018.
The Independent (2015): Two eagles mistake a drone for food in Austria. Online available at https://www.independent.co.uk/video/News/two-eaglesmistake-a-drone-for-food-in-austria-a6733351.html, last accessed on 14.05. 2018.

The Next Web (2017): Amazon patent details the scary future of drone delivery. Online available at https://thenextweb.com/tech/2017/08/24/amazonpatent-details-the-scary-future-of-drone-delivery, last accessed on 14.05.2018.

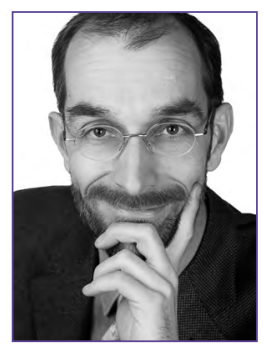

\section{PD DR. MICHAEL NENTWICH}

holds a Ph. D. in law and is director of the Institute of Technology Assessment (ITA) of the Austrian Academy of Sciences (ÖAW) in Vienna (since 2006). He is a passionate technology assessor (since 1987) as well as science and technology scholar and teacher.

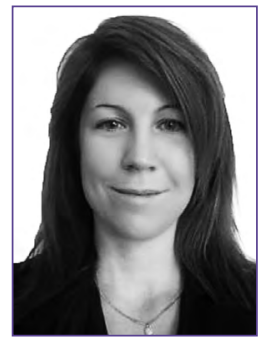

\section{DELILA M. HORVÁTH}

is a sociologist with a Master degree in Science and Technology Studies and is a member of the Space Generation Advisory Council.

\section{Nachhaltigkeit}

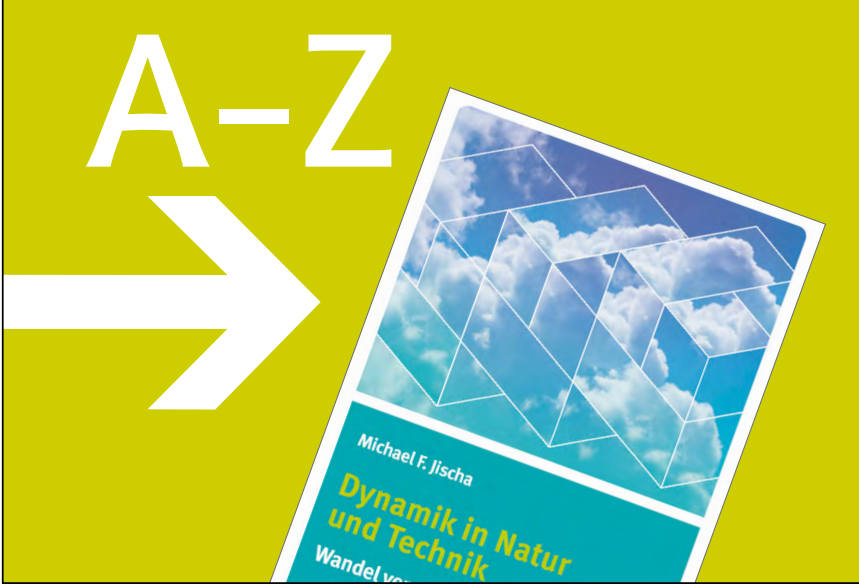

\section{wie Naturgesetze}

Warum kann ein Elefant einen Artgenossen nicht überspringen, während dies einem Hasen leicht gelingt? Was können wir von der Natur lernen - und können wir etwas gegen den Rückgang der Artenvielfalt tun? Diese und viele weitere Fragen können mit Blick auf die Naturgesetze beantwortet werden. Michael Jischa untersucht, wie sich unser Leben in Zeiten des technikgetriebenen, beschleunigten Wandels verändert - und er zeigt auf, vor welchen Herausforderungen wir heute stehen.

\section{F. Jischa}

\section{Dynamik in Natur und Technik}

Wandel verstehen und gestalten

348 Seiten, broschiert, 28,- Euro, ISBN 978-3-96238-040-3

Erhältlich im Buchhandel oder versandkostenfrei innerhalb Deutschlands bestellbar unter www.oekom.de 